\title{
A Single Amino Acid Change in Viral Genome-Associated Protein of Potato Virus Y Correlates with Resistance Breaking in 'Virgin A Mutant' Tobacco
}

\author{
Chikara Masuta, Mitsuyo Nishimura, Hiroshi Morishita, and Tatsuji Hataya
}

Laboratory of Plant Virology and Mycology, Faculty of Agriculture, Hokkaido University, Kita-ku, Kita 9, Nishi 9, Sapporo 060-8589, Japan. Accepted for publication 31 October 1998.

\begin{abstract}
Masuta, C., Nishimura, M., Morishita, H., and Hataya, T. 1999. A single amino acid change in viral genome-associated protein of potato virus $\mathrm{Y}$ correlates with resistance breaking in 'Virgin A Mutant' tobacco. Phytopathology 89:118-123.

Tobacco cultivar Virgin A Mutant (VAM) is reported to have the recessive potyvirus resistance gene $v a$. Varied levels of resistance were observed in VAM plants inoculated with Japanese potato virus Y (PVY) isolates. VAM was highly resistant to most of the PVY isolates tested and tolerant to three necrotic strain isolates of PVY-T. Based on data obtained from tissue printing and press blotting, the resistance appeared to be

mainly at the level of cell-to-cell movement. PVY replicated in VAM protoplasts, but the replication was $30 \%$ lower than in susceptible tobacco, suggesting that impairment of replication also contributes to resistance. To identify the viral gene product or products involved in VAM resistance, we isolated spontaneous resistance-breaking mutants by passing veinbanding (O strain) isolates several times through VAM plants. By comparing the amino acid sequences of the mutants with their original isolates, we identified a single amino acid substitution in the viral genome-associated protein $(\mathrm{VPg})$ domain that is correlated with VAM resistance breaking. Together, these results suggest that, in addition to its role in replication, VPg plays an important role in the cell-to-cell movement of PVY.
\end{abstract}

A viral infection cycle requires several complex steps: entry into a cell, genome replication, cell-to-cell movement, systemic spread through the phloem (long-distance movement), and transmission from plant to plant. If the cycle is interrupted at any step, infection will not be established. Plant defense against viral infection can occur through a number of mechanisms. Among these mechanisms, cultivar-specific resistance controlled by a resistance gene specific to a particular virus has proven to be the best long-term means of protection (2). Such resistance genes are considered to act directly or indirectly at a specific step in the viral infection cycle $(12,13)$. Cultivar-specific protection levels can range from tolerance to complete immunity; in a tolerant plant, the virus can multiply but does not cause disease symptoms. Under field conditions, even tolerance in the individual plant may be sufficient to provide efficient protection.

The Virgin A Mutant (VAM) tobacco cultivar contains a single gene that provides tolerance to some potyviruses including potato virus Y (PVY), tobacco vein mottling virus (TVMV), and tobacco etch virus (TEV) $(3,9)$. VAM was derived from cultivar Virgin A by X-ray irradiation and selection for resistance against PVY infection (6). The VAM resistance phenotype is associated with the recessive $v a$ gene and has been incorporated into many tobacco breeding lines $(3,5,9,18)$. Tolerance levels vary depending on the virus strain and isolate $(3,5,9,10,18)$. It has been reported that although symptoms of PVY were less severe in VAM cultivars, virus concentrations were equivalent to those found in susceptible tobacco (9). On the other hand, Sato and Kawamura (18) have reported that some Japanese tobacco cultivars containing the va gene show a high level of resistance against PVY infection. Latorre and Flores (10) found that VAM is apparently immune to 15 of 24 necrotic PVY isolates tested. Recently, the molecular mechanism of resistance mediated by the $v a$ gene was studied using two strains of TVMV: TVMV-WT and TVMV-S. A cultivar containing the $v a$

Corresponding author: C. Masuta; E-mail address: masuta@res.agr.hokudai.ac.jp

Publication no. P-1998-1204-01R

(C) 1999 The American Phytopathological Society gene was found to be tolerant to TVMV infection, but TVMV-S could break va gene resistance $(14,15)$. Based on these data, resistance seems to be due to restriction of viral cell-to-cell movement. The viral genome-associated protein (VPg) varied at a maximum of four amino acids that are likely to be responsible for resistance breaking by TVMV-S (15).

For potyviruses, the nuclear inclusion body protein a (NIa) consists of VPg at its N-terminus and a proteinase domain (Pro) at its C-terminus. The VPg domain is required for genome replication and long-distance movement (19). Whether the VPg is also involved in cell-to-cell movement remains unclear. Viral cell-to-cell movement of many plant viruses is mediated by so-called movement proteins (MPs) that are thought to have the ability to increase plasmodesmata size-exclusion limit (17). The relationship between VPg and MP is discussed in this paper.

Considering variability of reported PVY resistance in VAM cultivars, we designed experiments to determine whether the $v a$ gene is effective against Japanese isolates of PVY. We also examined $v a$ gene resistance against PVY and the site of resistance in the viral infection cycle. Using comparative studies, we predict a single amino acid mutation that may regulate the resistance breaking of some spontaneous PVY mutants.

\section{MATERIALS AND METHODS}

Virus isolates and host plants. PVY isolates $\mathrm{PVY}_{\mathrm{H}}, \mathrm{PVY}_{\mathrm{H}} \mathrm{T}_{13}$, PVY-Y7, PVY-YNA, and PVY-36 have been maintained in our laboratory (7). PVY-O $\mathrm{JT}_{\mathrm{JT}}$ and PVY-T ${ }_{\mathrm{JT}}$ were from Japan Tobacco, Inc. (Yokohama, Japan). The other isolates were obtained from the Hokkaido Chuo Station of the National Center for Seeds and Seedlings. PVY-O $_{\text {JT }}$ and PVY-T JT $_{\text {T }}$ were originally from tobacco, while the other isolates were isolated from potatoes. All PVY isolates were propagated in tobacco. Resistance-breaking isolates were maintained through VAM plants. Japanese PVY isolates are classified either as vein-banding (O) strains or necrosis (T) strains (Table 1). In Japan, necrosis strains have been conventionally classified as PVY-T, which was found to belong to the PVY ${ }^{\mathrm{N}}$ group (7). Nicotiana tabacum $\mathrm{cv}$. 
Bright Yellow 4 (BY), N. tabacum cv. Xanthi nc, and N. tabacum cv. VAM were used as indicated. Cultivars BY and Xanthi nc were used as susceptible controls, because they develop distinct symptoms when infected by either PVY-T or PVY-O. Inoculum was prepared by grinding PVY-infected BY or VAM leaves 1:10 (wt/vol) with $0.1 \mathrm{M}$ phosphate buffer, $\mathrm{pH}$ 7.0. The largest leaves of 6-weekold tobacco plants were rub-inoculated. The plants were grown at 23 to $27^{\circ} \mathrm{C}$ under natural light conditions in the greenhouse.

Tissue printing and press blotting. Tissue prints and press blots were prepared essentially as described by Holt (8). For tissue prints

TABLE 1. Response of tobacco cultivars to potato virus Y (PVY) isolates

\begin{tabular}{|c|c|c|c|}
\hline \multirow[b]{2}{*}{ Strains } & \multirow[b]{2}{*}{ Isolates } & \multicolumn{2}{|c|}{ Plants showing symptoms/inoculated plants ${ }^{\mathrm{a}}$} \\
\hline & & $B Y^{b}$ & VAM $^{c}$ \\
\hline \multirow[t]{12}{*}{$\mathrm{T}$} & $\mathrm{T}_{13}$ & $5 / 5(\mathrm{~T})$ & $5 / 5(\mathrm{~T})^{\mathrm{d}}$ \\
\hline & $\mathrm{T}_{\mathrm{JT}}$ & $5 / 5(\mathrm{~T})$ & $5 / 5(\mathrm{~T})^{\mathrm{d}}$ \\
\hline & SN & $5 / 5(\mathrm{~T})$ & $0 / 5$ \\
\hline & $\mathrm{C} 2$ & $5 / 5(\mathrm{~T})$ & $0 / 5$ \\
\hline & $\mathrm{C} 3$ & $5 / 5(\mathrm{~T})$ & $0 / 5$ \\
\hline & $\mathrm{C} 12$ & $5 / 5(\mathrm{~T})$ & $0 / 5$ \\
\hline & N3 & $5 / 5(\mathrm{~T})$ & $0 / 5$ \\
\hline & N4 & $5 / 5(\mathrm{~T})$ & $4 / 5(\mathrm{~T})^{\mathrm{d}}$ \\
\hline & G3 & $5 / 5(\mathrm{~T})$ & $0 / 5$ \\
\hline & G4 & $5 / 5(\mathrm{~T})$ & $0 / 5$ \\
\hline & ShiT & $5 / 5(\mathrm{~T})$ & $0 / 5$ \\
\hline & 442 & $5 / 5(\mathrm{~T})$ & $0 / 5$ \\
\hline \multirow[t]{6}{*}{$\mathrm{O}$} & $\mathrm{O}_{\mathrm{JT}}$ & $5 / 5(\mathrm{~T})$ & $0 / 5$ \\
\hline & YNA & $5 / 5(\mathrm{~T})$ & $5 / 5(\mathrm{O})^{\mathrm{e}}$ \\
\hline & $\mathrm{O}_{\mathrm{H}}$ & $5 / 5(\mathrm{~T})$ & $1 / 5(\mathrm{O})$ \\
\hline & 36 & $5 / 5(\mathrm{~T})$ & $0 / 5$ \\
\hline & Y7 & $5 / 5(\mathrm{~T})$ & $5 / 5(\mathrm{O})^{\mathrm{e}}$ \\
\hline & ShiO & $5 / 5(\mathrm{~T})$ & $0 / 5$ \\
\hline
\end{tabular}

a Assessed 1 month after inoculation. Letter in parentheses indicates symptoms; $\mathrm{T}$ and $\mathrm{O}$ represent the symptoms of PVY-T (typical symptom is necrosis) and PVY-O (typically induces vein banding), respectively.

${ }^{\mathrm{b}} \mathrm{BY}=$ Nicotiana tabacum $\mathrm{cv}$. Bright Yellow 4.

c VAM = Nicotiana tabacum $\mathrm{cv}$. Virgin A Mutant.

d VAM plants inoculated with these isolates showed delay ( $\sim 7$ days) in symptom development.

${ }^{\mathrm{e}}$ Isolates found to be resistance breaking of VAM, because there was no difference in symptom development between VAM and BY.
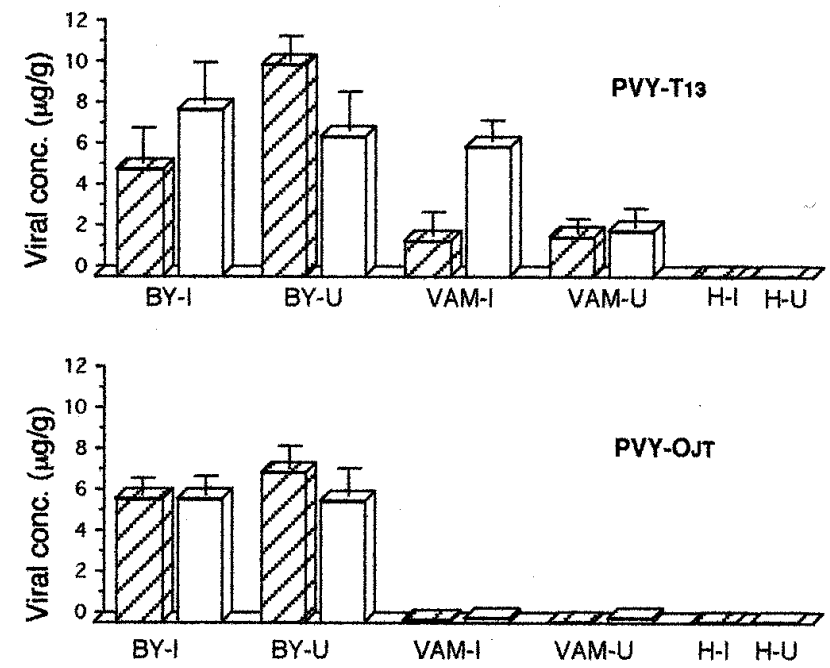

Fig. 1. Accumulation of virus in Nicotiana tabacum cvs. Bright Yellow 4 (control) and Virgin A Mutant plants inoculated with potato virus Y (PVY)- $\mathrm{T}_{13}$ and $\mathrm{PVY}_{\mathrm{JT}}$. Viral accumulation was determined by enzyme-linked immunosorbent assay (ELISA), and the measured values were converted to micrograms of virus per gram of tissue. Each histogram represents the mean ELISA values $\left(A_{405}\right)$ obtained from four individual plants. Standard deviations were indicated on each bar. Hatched and open histograms = viral concentrations 14 and 30 days after inoculation, respectively; I and $\mathrm{U}=$ inoculated leaf and upper leaf (after 14 days, second leaf; and after 30 days, eighth leaf above inoculated), respectively; and $\mathrm{H}=$ healthy negative control. of stem sections, 10 or 14 days after inoculation, stem sections were cut perpendicularly to the plant axis and pressed onto a nitrocellulose membrane. For tissue prints of leaf sections, leaf sections were cut perpendicularly to the midrib axis of the leaf. Leaves were harvested at 4, 7, 10, and 14 days postinoculation. Each cut surface was printed onto a membrane side by side. For press blots, the second upper leaf above the inoculated leaf was detached 14 days after inoculation and transferred onto nitrocellulose with the bottom surface of the leaf in direct contact with the membrane. This sandwich of leaves and nitrocellulose was pressed with 60 to $70 \mathrm{~kg} / \mathrm{cm}^{2}$ for $1 \mathrm{~min}$ by a hand compressor. The prepared membranes were incubated with anti-PVY-T primary monoclonal antibody and then with rabbit anti-mouse immunoglobulin alkaline phosphatase conjugate. The color was developed in $15 \mathrm{ml}$ of the substrate solution (100 mM Tris- $\mathrm{HCl}, \mathrm{pH} 9.5 ; 100 \mathrm{mM} \mathrm{NaCl}$; and $5 \mathrm{mM} \mathrm{MgCl}_{2}$ ) containing $100 \mu \mathrm{l}$ of $50 \mathrm{mg}$ of nitro blue tetrazolium per $\mathrm{ml}$ of $70 \%$ dimethylformamide and $50 \mu \mathrm{l}$ of $25 \mathrm{mg}$ of 5-bromo-4-chloro-3indolyl phosphate per $\mathrm{ml}$ of dimethylformamide.

Protoplast inoculation. Preparation of protoplasts was as described previously (11). About $10^{5}$ protoplasts from BY or VAM were inoculated with $2 \mu \mathrm{g}$ of purified virus in the presence of 25 to $30 \%$ polyethylene glycol 1540 and $2 \mathrm{mM} \mathrm{CaCl}_{2}$. After a 2-day incubation under continuous light at $28^{\circ} \mathrm{C}$, virus accumulation was determined by conventional enzyme-linked immunosorbent assay (ELISA) with anti-PVY-O $\mathrm{H}_{\mathrm{H}}$ polyclonal antibody. The harvested cells were
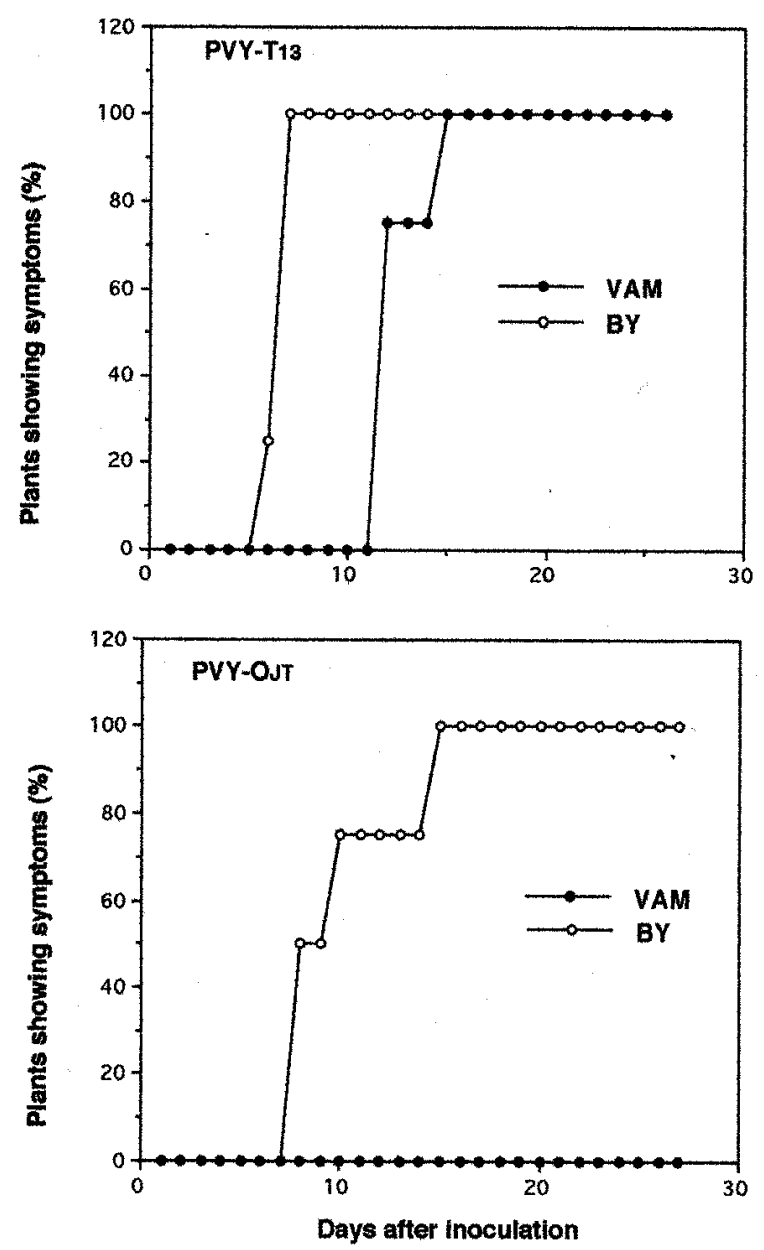

Fig. 2. Development of systemic symptoms in Nicotiana tabacum cvs. Bright Yellow 4 (BY) and Virgin A Mutant (VAM) after inoculation of potato virus Y (PVY)- $\mathrm{T}_{13}$ and PVY-O $\mathrm{JT}_{\mathrm{JT}}$. Each virus isolate was inoculated onto Carborundumdusted leaves of 30 plants with sap from systemically infected BY leaves in $0.1 \mathrm{M}$ phosphate buffer ( $\mathrm{pH}$ 7.0). VAM plants infected with PVY-T ${ }_{13}$ showed a 7-day delay in symptom development, and the amount of virus in plants was significantly lower than in the control; similar results were observed when infected with PVY-T ${ }_{\mathrm{JT}}$ and PVY-N4 (data not shown). 
ground in $1 \mathrm{ml}$ of phosphate-buffered saline containing $0.05 \%$ Tween 20 and the supernatant was used for ELISA assay after centrifugation.

Sequence analysis. Double-stranded cDNA for each gene of PVY was synthesized, prepared by conventional reverse-transcriptase polymerase chain reaction and inserted into general cloning vectors. Sequences of all cDNA clones were determined using the Thermo Sequenase Cycle-Sequencing kit (Amersham International plc., Buckinghamshire, United Kingdom) for the Model 4000L LI-COR automated DNA sequencer (LI-COR, Lincoln, NE). At least three independent clones for each gene were sequenced. Sequences were analyzed with DNASIS, version 3.0 (Hitachi Software Engineering Co. Ltd., Tokyo) or Gene Works (version 2.5; Oxford Molecular Group, Inc., Beaverton, OR).

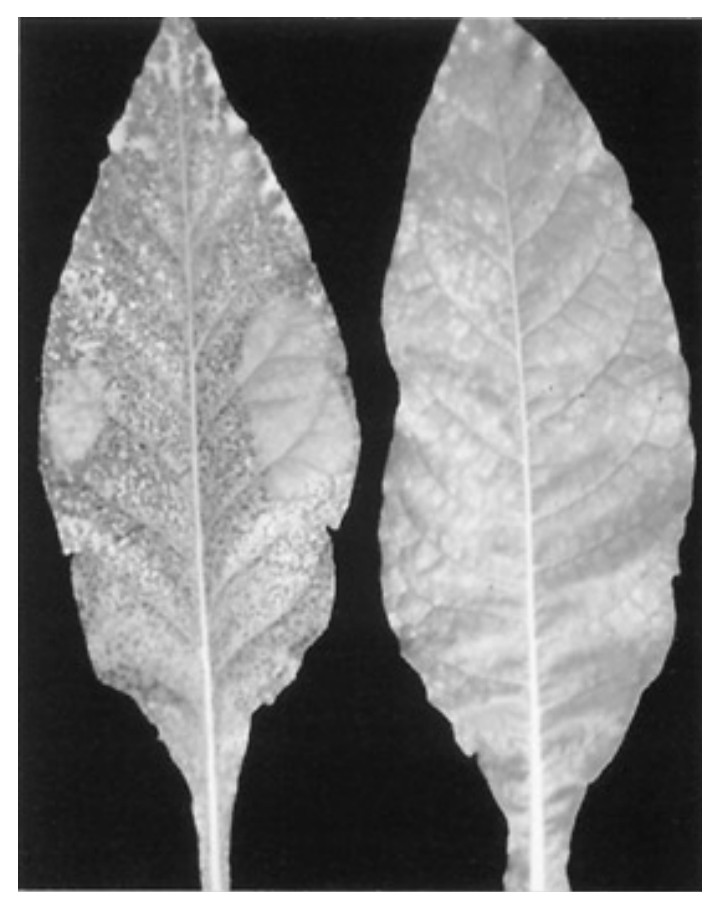

Fig. 3. Symptoms on the upper top leaves of Nicotiana tabacum cvs. Bright Yellow 4 (left) and Virgin A Mutant (VAM; right) 30 days after inoculation with potato virus $\mathrm{Y}$ (PVY)- $\mathrm{T}_{13}$. VAM leaves show milder symptoms with a decreased number of necrotic spots.

\section{RESULTS}

VAM resistance response to infection with Japanese PVY isolates. To investigate the nature of $v a$ gene resistance to PVY, we tested the VAM response to 18 Japanese PVY isolates. Among them, 12 isolates are classified as T strains, which induce necrosis on tobacco, and the other 6 as $\mathrm{O}$ strains, which induce chlorotic mottle and vein banding on tobacco and local lesions on Chenopodium amaranticolor. Cultivar BY plants were highly susceptible to all PVY isolates, whereas VAM was highly resistant to 13 isolates of both $\mathrm{O}$ and $\mathrm{T}$ strains and tolerant to 3 T-strain isolates (Table 1). VAM was found to be susceptible to the two O-strain isolates, PVY-YNA and PVY$\mathrm{Y} 7$, that were therefore classified as resistance-breaking isolates. After these initial inoculation experiments, we tried to generate some resistance-breaking mutants by repeated inoculations of PVY onto VAM. No mutants belonging to PVY-T were obtained, but we obtained several mutants from the PVY-O isolates. Of the 50 plants inoculated with $\mathrm{PVY}-\mathrm{O}_{\mathrm{H}}, 11$ became infected with resistance-breaking mutants $\mathrm{PVY}-\mathrm{O}_{\mathrm{HB}}$, while only 3 plants out of 100 showed disease symptoms when inoculated with PVY-36, thus indicating that they harbored a resistance-breaking variant (PVY-36B). After several passages through VAM plants, $\mathrm{PVY}-\mathrm{O}_{\mathrm{HB}}$ and PVY-36B were established as completely resistance-breaking mutants. Most of the

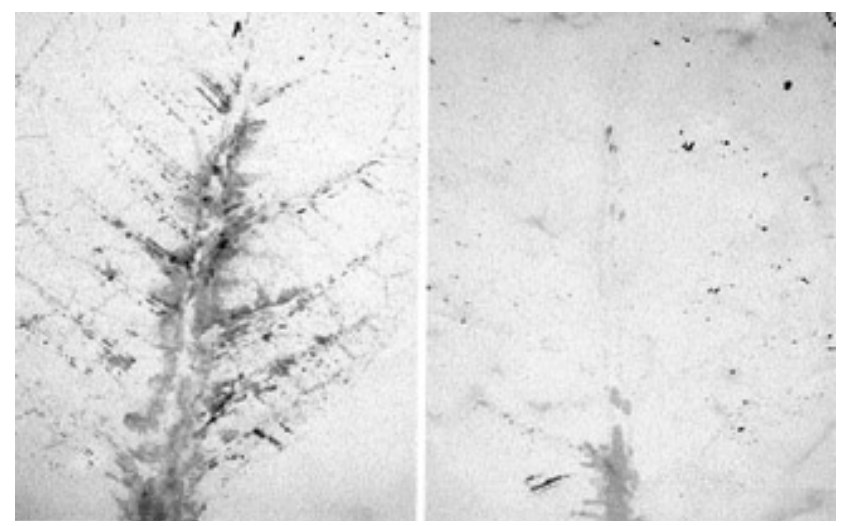

Fig. 5. Potato virus Y (PVY) location and distribution in entire leaves of Nicotiana tabacum cvs. Bright Yellow 4 (left) and Virgin A Mutant (right) plants. Second upper leaf above inoculated leaf 14 days after inoculation with PVY$\mathrm{T}_{13}$ was press-blotted to membrane and incubated with anti-PVY antibody.
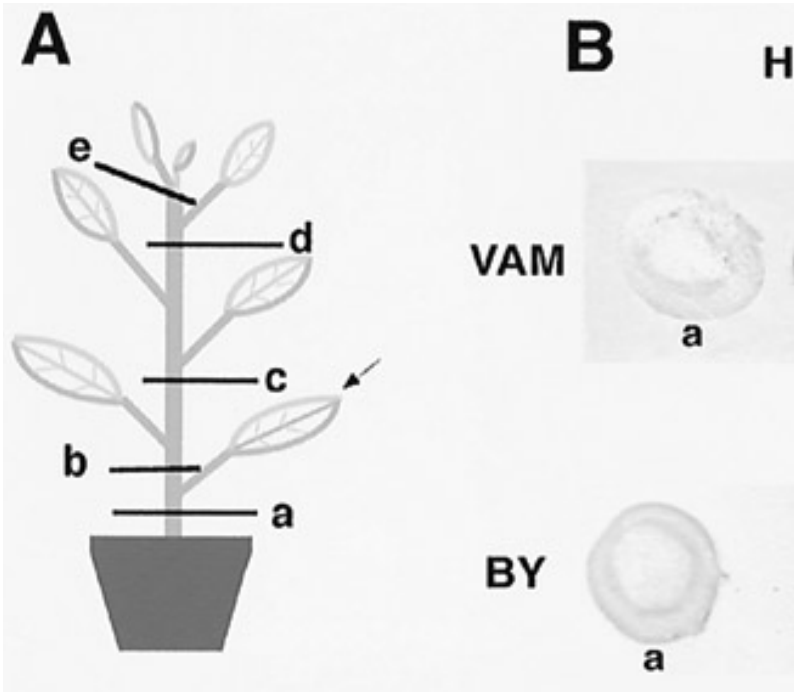

H

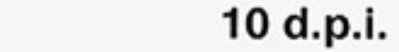

C

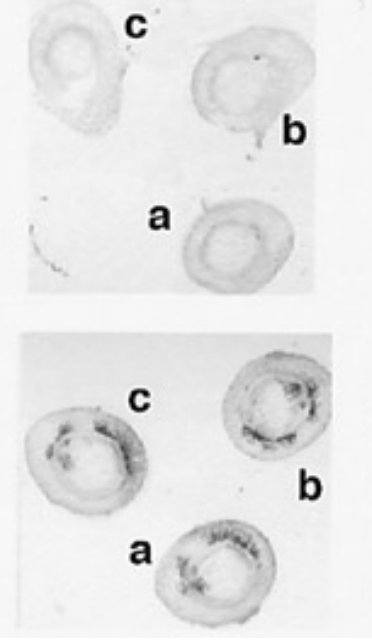

14 d.p.i.
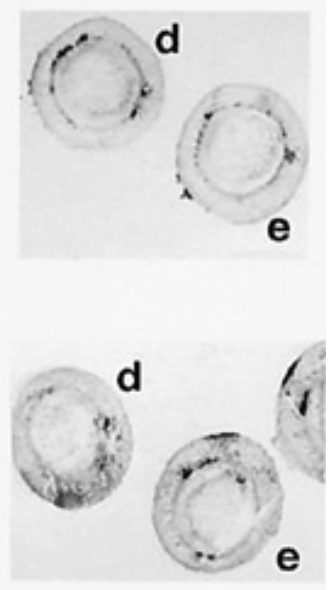

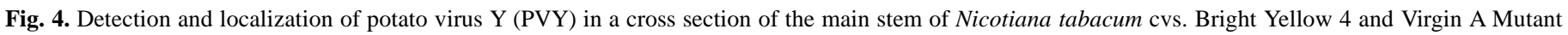

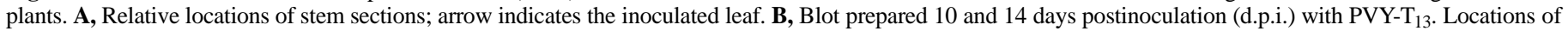
the cross section are shown by the lines labeled 'a' to 'e.' The section labeled 'a' was made below the inoculated leaf (lowest in the case of the illustration). 
PVY isolates we used did not induce systemic symptoms, and we were not able to detect virus in the inoculated leaves (Table 1, Fig. 1). Therefore, VAM is highly resistant to those PVY isolates. Only three isolates (PVY-T 13, PVY-T $_{\mathrm{JT}}$, and PVY-N4) moved systemically, but a symptom delay (by 7 days) (Fig. 2) was observed and the infected plants showed much milder symptoms on the young upper leaves 1 month after inoculation; VAM is thus resistant to those three isolates. As the plants grew, disease severity tended to decrease even in the susceptible BY (or Xanthi nc) plants, but the upper VAM leaves showed much milder symptoms (decrease in numbers of necrotic spots and in lesion sizes) by the flowering stage (Fig. 3). We classified this symptom change as recovery.

Virus accumulations in VAM. BY and VAM plants were inoculated with either the necrosis isolate PVY-T $\mathrm{T}_{13}$ or the vein-banding isolate PVY-O ${ }_{\mathrm{JT}}$, and levels of viral accumulation were deter- mined by ELISA in both inoculated and uninoculated upper leaves 14 and 30 days after inoculation. PVY-O ${ }_{\text {JT }}$ was not detected in either inoculated or uninoculated leaves of VAM after 14 and 30 days (Fig. 1). The PVY-T ${ }_{13}$ concentration in the inoculated VAM leaves was slightly lower than in BY leaves, whereas it was approximately 25 to $30 \%$ of the control level in the upper leaves showing recovery (Fig. 1). Therefore, the leaves showing mild symptoms had a lower level of viral accumulation.

Localization of PVY in stem tissues by tissue printing and press blotting. Virus localization prints were prepared from cross sections of tobacco plants infected with PVY-T 13 and 14 days after inoculation. Viral antigen was detected in the inner and outer phloem rings in all the stem sections prepared from BY (Fig. 4). In contrast, the stem sections from VAM did not contain viral antigen after 10 days, and relatively low levels of viral antigen were

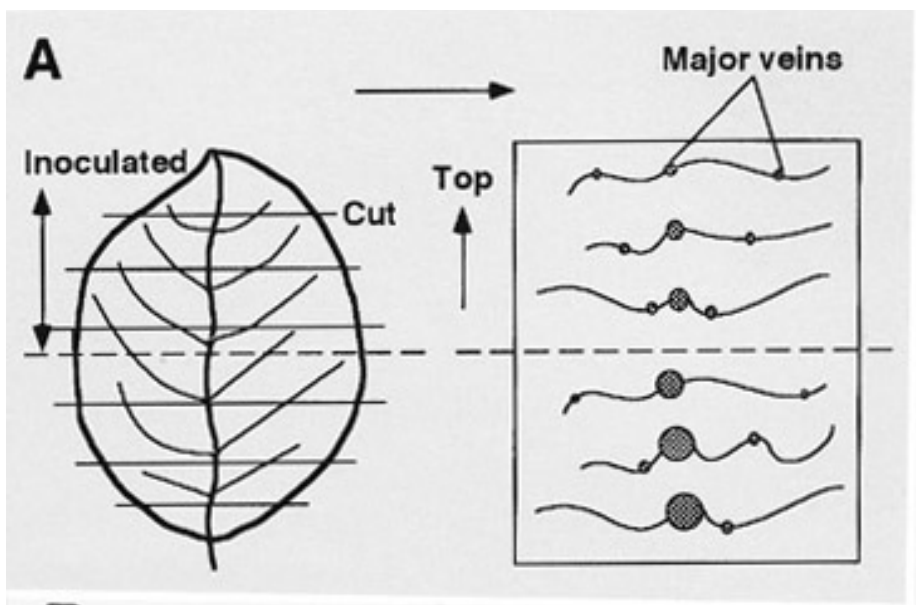

B

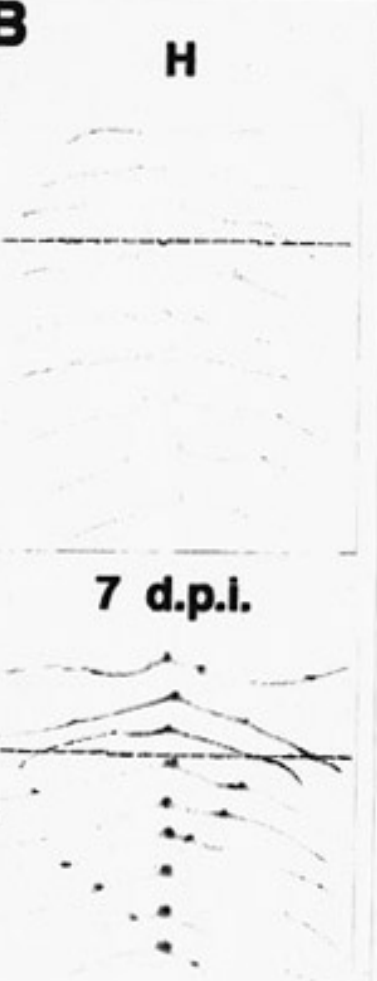

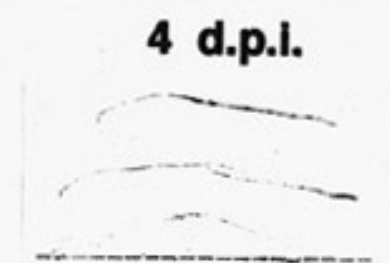
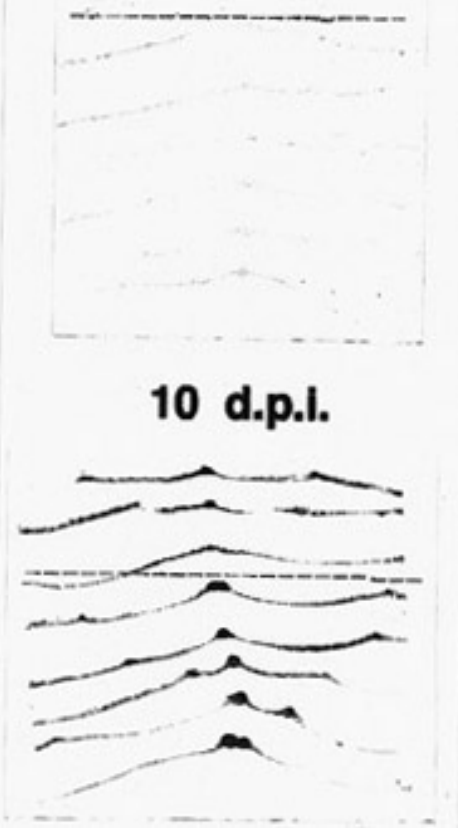

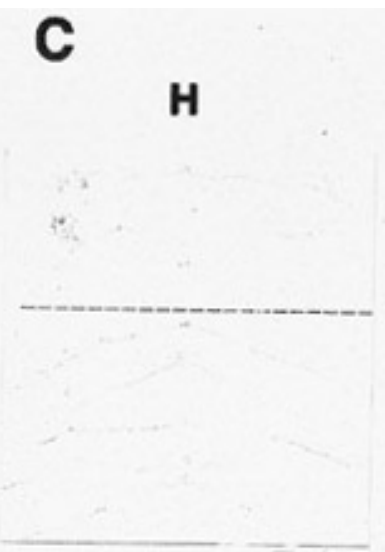

7 d.p.l.

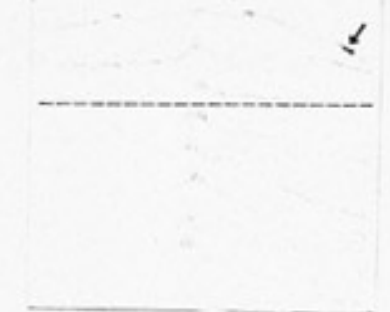

12 d.p.l.
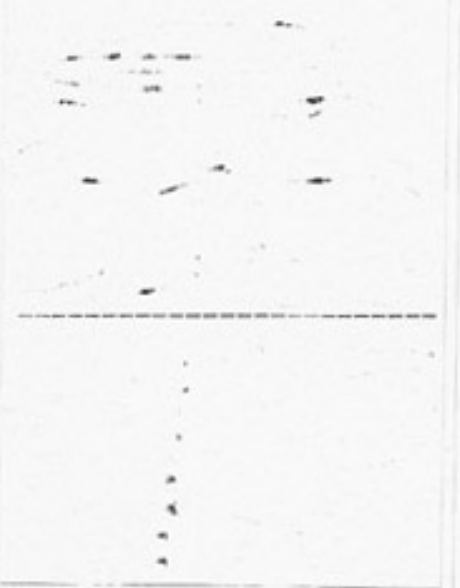

4 d.p.l.
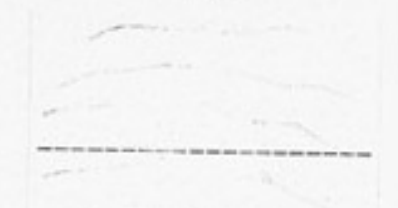

10 d.p.l.

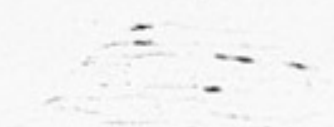

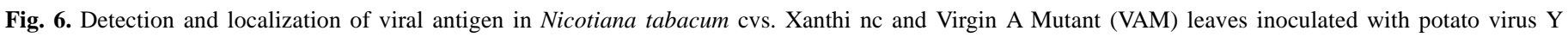

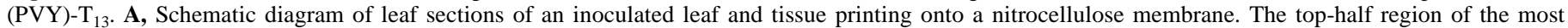

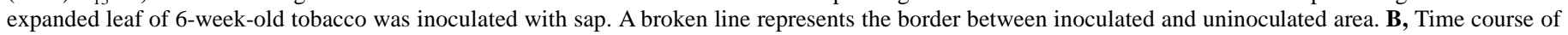

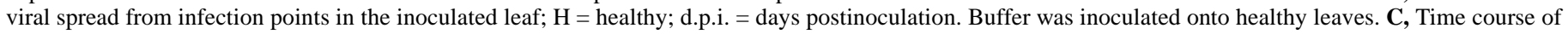
viral spread from infection points in VAM leaves inoculated with PVY-T . $_{13}$ 


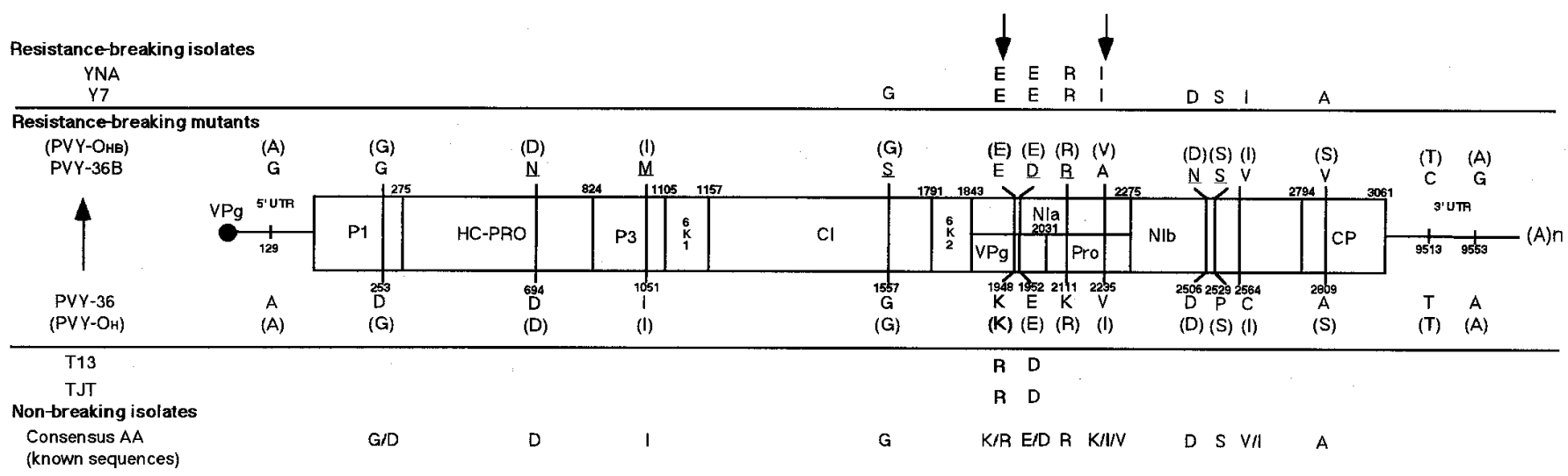

Fig. 7. Amino acid substitutions in resistance-breaking mutants and their original isolates. Complete amino acid sequences of potato virus $\mathrm{Y}$ (PVY)-36 and PVY-36B were compared; differences between the two sequences are indicated. Amino acids of $\mathrm{PVY}-\mathrm{O}_{\mathrm{H}}$ and $\mathrm{PVY}-\mathrm{O}_{\mathrm{HB}}$ are indicated in parentheses at the residues corresponding to the differences between PVY-36 and PVY-36B. The arrow indicates the transition from the original isol ates to the resistance-breaking mutants. Common differences occur at positions 1,948 and 2,235 between both PVY-36 and PVY-36B, and PVY-O ${ }_{\mathrm{H}}$ and PVY-O $\mathrm{O}_{\mathrm{HB}}$ (marked with arrows). Sequences of the clones surrounding the nuclear inclusion body protein a (NIa) gene of two other resistance-breaking isolates (PVY-YNA and PVY-Y7) were also determined; amino acids are indicated above the top line aligned with the differences between PVY-36 and PVY-36B. Below the bottom line, the amino acid consensus among the published PVY isolates is shown. On the 5' and $3^{\prime}$ noncoding regions, nucleotide differences are shown. Underlined amino acids indicate changes to equivalent amino acids.

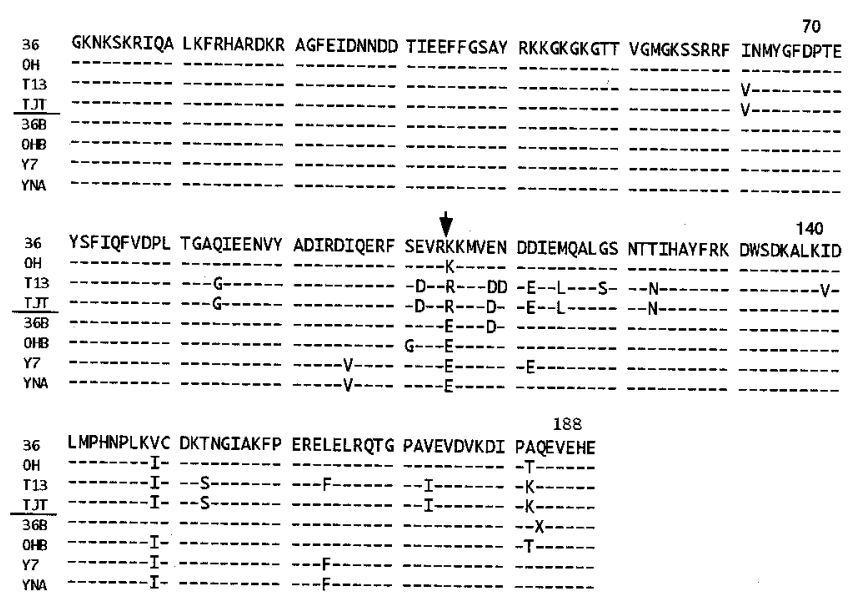

Fig. 8. Alignment of the amino acid sequences of the viral genome-associated proteins of eight potato virus Y isolates. Four isolates (PVY-36B, PVY$\mathrm{O}_{\mathrm{HB}}, \mathrm{PVY}-\mathrm{Y} 7$, and PVY-YNA) are resistance breaking. The arrow indicates the amino acid unique only for resistance-breaking isolates.

detected after 14 days. To determine virus location and distribution in entire leaves, we used press blotting. Virus was detected only along the major veins in the second upper leaf above the inoculated leaf of a VAM plant 14 days after inoculation, while it was widely distributed in the corresponding leaf of BY (Fig. 5).

Localization of PVY in leaf tissues by tissue printing. Only three PVY isolates were detected in the inoculated leaves; therefore, it is likely that other PVY isolates were not able to move from the infection sites, possibly due to difficulty in cell-to-cell movement in VAM leaves. To further analyze the resistance mechanisms, we performed tissue-print immunoassays using PVY- $\mathrm{T}_{13}$, because it is one of the isolates that we can detect in the inoculated leaves. Viral spread from the infection points on the VAM leaves appeared to be very slow compared with those on Xanthi nc (Fig. 6). This initial delay of viral spread seems to lead to a consequent delay in the development of systemic symptoms on VAM plants (Fig. 2 ). Virus was not detected in major veins of VAM leaves at 4, 7 , and 10 days postinoculation, but was observed as spread from the infection points (on days 7, 10, and 12). It was not until the day 12 that virus was detected in major veins of the VAM leaves. Once the virus moved into major veins, it spread quickly over the inoculated leaf.
Protoplast inoculation. To determine if a virus can multiply at the single-cell level, BY and VAM protoplasts were inoculated with PVY-36, an isolate that is not able to infect intact VAM plants, and with PVY-36B, a resistance-breaking isolate. The viral replication in VAM and BY protoplasts was measured by ELISA using coat protein antisera after 2 days of incubation. PVY-36 was able to replicate in VAM protoplasts, but accumulation was $30 \%$ lower than in the BY control. PVY-36B accumulated to the same level in VAM protoplasts as in the BY protoplasts.

Nucleotide and amino acid sequences of wild-type and resistance-breaking PVY isolates. To determine if nucleotide or amino acid substitutions in the PVY genome correlates with resistance breaking, the entire nucleotide sequence of the resistance-breaking mutants PVY-36B and PVY-O $\mathrm{HB}_{\mathrm{HB}}$ were determined and compared with the original isolates PVY-36 and PVY-O $\mathrm{H}_{\mathrm{H}}$. A mutation at the same position in PVY-36B and PVY- $\mathrm{O}_{\mathrm{HB}}$ would suggest a strong possibility that the change was directly linked to VAM resistance breaking. There were two distinct and consistent differences between PVY-36 and PVY-36B, and PVY-O ${ }_{\mathrm{H}}$ and PVY-O $\mathrm{O}_{\mathrm{HB}}$, at amino acids 1,948 and 2,235 in the NIa-VPg and NIa-Pro domains, respectively (Fig. 7). To rule out coincidence, we sequenced the NIa regions of two other resistance-breaking isolates (PVY-YNA and PVY-Y7). A comparison of the amino acid sequences of the VPgs from eight isolates is shown in Figure 8. All resistance-breaking PVYs examined encode a glutamate at amino acid 1,948, whereas nonbreaking PVYs encode a lysine (or an arginine) at this position. In the case of substitution at amino acid 2,235, no amino acid was conserved among the resistance-breaking isolates. Moreover, some variable amino acids occupy this position in other published PVY sequences $(20,21)$, suggesting that this position may be a variable position and thus may not be involved in resistance breaking. No consistent nucleotide substitutions common to all resistancebreaking isolates were identified.

\section{DISCUSSION}

Based on the observations of ELISA and tissue printing, VAM resistance appears to be at the level of cell-to-cell movement from the infection sites. A delay of the viral spread from the initial infection points will result in a delay in the viral loading into minor veins (classes IV and V) that form a network all over a leaf (16). When virus is detected in the major veins, the viral concentration reaches a high level in the phloem, and virus is rapidly unloaded from the veins (class III); at this point, the virus spreads over the 
inoculated leaf. In addition, the consecutive systemic symptoms appear to develop similarly to the control susceptible plants. It is, therefore, unlikely that major restriction occurs at the level of the viral loading into the phloem-sieve element. As the infected plants age, the young upper leaves show milder symptoms, corresponding to a lower concentration of the virus when compared with the control. VAM resistance against PVY-T ${ }_{13}$ seems to be effective when the viral concentration is under a certain threshold. There are two possibilities for this low viral concentration. One is that the virus cannot be efficiently unloaded from the phloem, and the other is that the virus can not move from cell to cell although it is unloaded efficiently from the phloem. In the inoculated leaves, resistance appears to be at the point of viral spread from the infection sites; therefore, it is likely that symptom recovery is also due to deficiency in cell-to-cell movement. However, at this time, we cannot conclusively refute the former possibility. It is possible that the resistance mechanisms operate at both levels: cell-to-cell movement and long-distance movement. Our results are consistent with what is known about va resistance to TVMV, which has been shown to restrict cell-to-cell movement (4). The limitation of PVY infection may be due to the same molecular mechanism reported for TVMV. The VPgs of TVMV and PVY may fold into similar structures that form a complex with host factors either alone or together with other viral proteins, and the resulting protein complex is required for efficient cell-to-cell movement. We suggest that, in VAM plants, the recessive $v a$ gene results in the production of a defective protein normally produced by the hypothetical gene $V A$ and that the complex necessary for viral cell-to-cell movement is not formed, and this results in resistance. Amino acid substitutions in the VPg domain would, thus, enable VPg to adapt to the alternative (defective, $v a$ ) isoform of the $V A$ gene product. The primary structures of the PVY and TVMV VPgs are quite different, but the secondary structures predicted by the Chou-Fasman method are similar, especially in the C-terminal region (data not shown). As many as four amino acid substitutions in the VPg of TVMV, which are clustered, were shown to be necessary for overcoming va resistance (15). We have also specified one amino acid substitution ( $\mathrm{Lys}_{1948}$ or $\mathrm{Arg}_{1948}$ to $\mathrm{Glu}_{1948}$ ) in the VPg domain of PVY. A substitution of acidic amino acid glutamate for basic amino acid lysine (or arginine) is likely to affect the biochemical property of the entire VPg. In the two VPgs of TVMV and PVY, these amino acid substitutions were at structurally similar locations. Furthermore, substitutions from a basic to an acidic amino acid in the VPg of resistance-breaking isolates resulted in a decrease in the calculated $\mathrm{pI}$ values for VPg compared with nonbreaking isolates. Change in the $\mathrm{pI}$ value may induce a conformational change and drastically affect the ability of the protein to interact with other molecules.

In contrast to most other virus groups, potyvirus movement seems to be driven by proteins with other functions (1). VPg is a protein covalently attached to the 5' end of genomic RNA and involved in replication. Furthermore, Schaad et al. (19) recently reported that TEV VPg may be necessary for long-distance movement (19). Taken together, not only is the VPg protein required for replication of the viral genome and long-distance movement, but, according to our data, it is also involved in cell-to-cell movement. Rojar et al. (17) demonstrated that the VPg of bean common mosaic potyvirus did not exhibit viral MP properties but the capsid protein (CP) and the helper component-proteinase (HC-Pro) behaved as cell-to-cell MPs (17). At this stage, there is no evidence that potyvirus VPg can directly interact either with $\mathrm{CP}$ or HC-Pro, but these proteins probably make a nucleoprotein complex with viral RNA attached with VPg. VPg may subsequently act to facilitate the delivery of this complex to plasmodesmata by its interaction with a host factor.

\section{ACKNOWLEDGMENTS}

This research was supported by Grant-in-Aid for Scientific Research no. 09660355 from the Ministry of Education, Science, and Culture, Japan. We thank I. Uyeda, Hokkaido University, for helpful discussions; and M. Sato, the Hokkaido Chuo Station of the National Center for Seeds and Seedlings, for providing us with potato virus $\mathrm{Y}$ isolates.

\section{LITERATURE CITED}

1. Carrington, J. C., Kasschau, K. D., Mahajan, S. K., and Schaad, M. C. 1996. Cell-to-cell and long-distance transport of viruses in plants. Plant Cell 8:1669-1681.

2. Crute, I. R., and Pink, D. A. C. 1996. Genetics and utilization of pathogen resistance in plants. Plant Cell 8:1747-1755.

3. Fischer, D. B., and Rufty, R. C. 1993. Inheritance of partial resistance to tobacco etch virus and tobacco vein mottling virus in burley tobacco cultivar Sota 6505. Plant Dis. 77:662-666.

4. Gibb, K. S., Hellmann, G. M., and Pirone, T. P. 1989. Nature of resistance of a tobacco cultivar to tobacco vein mottling virus. Mol. PlantMicrobe Interact. 2:332-339.

5. Gooding, Jr., G. V., and Kennedy, G. G. 1985. Resistance in tobacco breeding line NC 744 to potato virus Y and inoculation by aphids. Plant Dis. 69:396-397.

6. Gupton, C. L., and Burk, L. G. 1973. Location of the factor for resistance to potato virus $\mathrm{Y}$ in tobacco. J. Hered. 64:289-290.

7. Hataya, T., Inoue, A. K., Ohshima, K., and Shikata, E. 1994. Characterization and strain identification of a potato virus $\mathrm{Y}$ isolate non-reactive with monoclonal antibodies specific to the ordinary and necrotic strains. Intervirology 37:12-19.

8. Holt, C. A. 1992. Detection and localization of plant pathogens. Pages 125-137 in: Tissue Printing. P. D. Reid, R. F. Pont-Lezica, E. del Campillo, and R. Taylor, eds. Academic Press, Inc., San Diego, CA.

9. Johnson, M. C., and Pirone, T. P. 1982. Evaluation of tobacco introduction 1406 as a source of virus resistance. Phytopathology 72:68-71.

10. Latorre, B. A., and Flores, V. 1985. Strain identification and crossprotection of potato virus $\mathrm{Y}$ affecting tobacco in Chile. Plant Dis. 69: 930-932.

11. Masuta, C., Tanaka, H., Uehara, K., Kuwata, S., Koiwai, A., and Noma, M. 1995. Broad resistance to plant viruses in transgenic plants conferred by antisense inhibition of a host gene essential in S-adenosylmethionine-dependent transmethylation reactions. Proc. Natl. Acad. Sci. U.S.A. 92:6117-6121.

12. Meshi, T., Motoyoshi, F., Adachi, A., Watanabe, Y., Takamatsu, N., and Okada, Y. 1988. Two concomitant base substitutions in the putative replicase genes of tobacco mosaic virus confer the ability to overcome the effects of a tomato resistance gene, Tm-1. EMBO (Eur. Mol. Biol. Organ.) J. 7:1575-1581.

13. Meshi, T., Motoyoshi, F., Maeda, T., Yoshioka, S., Watanabe, H., and Okada, Y. 1989. Mutations in the tobacco mosaic virus 30-kDa protein gene overcome Tm-2 resistance in tomato. Plant Cell 1:515-522.

14. Nicolas, O., Dunnington, S. W., Gotow, L. F., Pirone, T. P., and Hellmann, G. M. 1997. Variations in the VPg protein allows a potyvirus to overcome va gene resistance in tobacco. Virology 237:452-459.

15. Nicolas, O., Pirone, T. P., and Hellmann, G. M. 1996. Construction and analysis of infectious transcripts from a resistance-breaking strain of tobacco vein mottling potyvirus. Arch. Virol. 141:1535-1552.

16. Roberts, A. G., Cruz, S. S., Roberts, I. M., Prior, D. A. M., Turgeon, R., and Oparks, K. J. 1997. Phloem unloading in sink leaves of Nicotiana benthamiana: Comparison of a fluorescent solute with a fluorescent virus. Plant Cell 9:1381-1396.

17. Rojas, M. R., Zerbini, M., Allison, R. F., Gilbertson, R. L., and Lucas, W. J. 1997. Capsid protein and helper component-proteinase function as potyvirus cell-to-cell movement proteins. Virology 237:283-295.

18. Sato, M., and Kawamura, S. 1974. Resistance to potato virus Y of a Japanese domestic tobacco, Enshu. Bull. Iwata Tobacco Exp. Stn. 6:23-28.

19. Schaad, M. C., Lellis, A. D., and Carrington, J. C. 1997. VPg of tobacco etch potyvirus is a host genotype-specific determinant for long-distance movement. J. Virol. 71:8624-8631.

20. Singh, M., and Singh, R. P. 1996. Nucleotide sequence and genome organization of a Canadian isolate of the common strain of potato virus Y (PVYO $)$. Can. J. Plant Pathol. 18:209-224.

21. Thole, V., Dalmay, T., Burgyan, J., and Balaza, E. 1993. Cloning and sequencing of potato virus Y (Hungarian isolates) genomic RNA. Gene 123:149-156. 